\title{
Comparison of Bacillus Calmette Guerin (BCG) Vaccine and Mitomycin C as an Adjuvant Therapy after the Surgical Excision of Bovine Ocular Squamous Cell Carcinoma
}

\author{
N. Priyanka ${ }^{1 *}$, B. N. Nagaraja ${ }^{2}$, N. Nagaraju ${ }^{3}$, D. R. Manjunath ${ }^{4}$ \\ and B. R. Balapannavar ${ }^{5}$ \\ ${ }^{1}$ Department of Veterinary Surgery and Radiology, Veterinary College, \\ KVAFSU, Bidar-585401, India \\ ${ }^{2}$ Department of Veterinary Surgery and Radiology, Veterinary College, \\ Bengaluru-560024, India \\ ${ }^{3}$ Department of Veterinary Surgery and Radiology, Veterinary College, Gadag -571201, India \\ ${ }^{4}$ Department of TVCC, Veterinary College, Hassan -573202, India \\ ${ }^{5}$ Department of Veterinary Surgery and Radiology, Veterinary College, \\ Hassan -573202, India \\ *Corresponding author
}

Keywords

Bacillus CalmetteGuerin (BCG) vaccine, Bovine ocular squamous cell carcinoma and Mitomycin C

Article Info

\section{Accepted:}

15 June 2021

Available Online:

10 July 2021
Ocular squamous cell carcinoma is the most common neoplasm of the eye in cattle. It is a primary neoplasm of epithelial origin which occurs in different ocular and periocular tissues. Bovine ocular squamous cell carcinoma (OSCC) also called "Cancer eye" represents the most economically important and malignant tumor among tumors affecting large animals. In group A six animals with third eyelid tumour after the surgical excision subjected to subcutaneous administration of BCG vaccine at 0,5 and 15 day. In group B six animals with third eyelid tumour after surgical excision subjected to administration of Mitomycin C $0.04 \%$ topically on alternate weeks for two months as adjunctive therapy. All the animals observed for a follow up period of six months for recurrence of tumor.

\section{Introduction}

Bovine ocular squamous cell carcinoma (OSCC) also called "Cancer eye" represents the most economically important and malignant tumor among tumors affecting large animals. The economic impact includes whole carcass condemnation about $12.6 \%$ (Heeney and Valli, 1985). The aetiology and predisposition of the disease is multifactorial, includes genetic susceptibility, breeds with circumocular apigmentation, age, ultraviolet 
radiation, viruses (BPV and $\mathrm{BHV}$ ). Rate of metastasis for ocular squamous cell carcinoma ranges from 0.03 to $15.4 \%$ (Schwink, 1987). Superficial keratectomy followed by irradiation in equines (Bosch and Klein, 2005), various successful treatment options surgical excision in combination with cryotherapy, hyperthermia, radiotherapy, chemotherapy and photodynamic therapyin horse (Taylor and Haldorson, 2013) and surgical excision followed by cauterization with $1 \%$ silver nitrate solution and immunotherapy in bovines (Dilipkumar and Patil, 2016).

BCG (Bacillus Calmette Guerin) vaccine stimulates B and T cells and natural killer cells activity, natural killer cells in turn stimulate interferons and cytokines. Interferons stimulates antitumor activity of macrophages, which interrupt the neoplastic process of squamous cell carcinoma in cattle (Radhakrishnan et al., 1999).

Mitomycin $\mathrm{C}$ is an antitumor antibiotic isolated from Streptomyces caespitosus. It is a bioreductive alkylating agent, inhibit crosslinking of DNA (Verweij and Pinedo, 1990).It is widely used systemically and as topical adjunctive therapy for the treatment of ocular malignancies.

\section{Materials and Methods}

The study was conducted on the clinical cases of cattle with third eyelid tumors, presented to the Department of Veterinary Surgery and Radiology, Veterinary College, Hassan. Twelve cases were randomly selected for the study and divided into two groups of six cattle each. Diagnosis was done based on the clinical signs and histopathological findings. On routine clinical, hemato-biochemical and ophthalmic examination revealed to be fit for surgery and adjuvant therapy. Surgical excision of the tumor was performed aseptically under sedatives and nerve blocks with standard surgical procedure.

In group A, animalssubjected to subcutaneous administration of BCG vaccine (Tubervac, Dheer Healthcare Private Limited, Mumbai) after surgical excision of third eyelid tumor on $0^{\text {th }}, 5^{\text {th }}$ and $10^{\text {th }}$ day post surgically. In Group B were instilled with $0.04 \%$ Mitomycin C eye drops after surgical excision of third eyelid tumor. It was instilled topically t.i.d., on alternate weeks for two months (Inj Mitomycin, Zydus Oncosciences, Nagpur, Maharashtra). Alterations in haematological parameters and serum biochemical parameters were estimated on the day of surgery, $1^{\text {st }}, 15^{\text {th }}$, $30^{\text {th }}$ and $60^{\text {th }}$ postoperative day. Tissues were collected in $10 \%$ formal saline and processed for histopathological findings. The efficacy of treatment was assessed based on recurrence of tumor in a follow up period of 6 months.

\section{Results and Discussion}

In the present study the third eyelid tumor mass appearedpapillomatous, papule, nodular, cauliflower and ulcerated growth protruding from the eye involving the nictitating membrane. Tumor size ranged between 0.5 to $1 \mathrm{~cm}$. On histopathological examination of surgically excised tumour samples diagnosed as squamous cell carcinoma, it was classified as well differentiated squamous cell carcinoma and poorly differentiated squamous cell carcinoma in cattle. The well differentiated squamous cell carcinomas were characterized by presence of large polyhedral cells with large nucleolus arranged in cords with intercellular bridges forming epithelial cell nests and containing concentric laminations of keratin in the form of "Keratin pearls" (Fig.1). Poorly differentiated squamous cell carcinoma were characterized by highly anaplastic cells with small hyper chromatic nuclei, high mitotic figures and no epithelial pearl formation (Fig.2). 
In the present study, hemato-biochemical values differ non - significantly between the groups throughout the study. In group I, no recurrence was observed in the other five cattle (Fig. 3) but, recurrence of the tumor was observed in one cattle, four months after surgical excision of the third eyelid tumor, after the observation period of six months. This is in correspondence with the findings of Panchbhai et al., (1987) who observed that $37.5 \%$ of the cases had complete cure. Dilipkumar and Patil (2016) who observed no recurrence of tumour, after the subcutaneous administration of $\mathrm{BCG}$ vaccine post surgically.

The recurrence of the ocular tumor observed in one cow after four months might be due to invasion of the cancerous cell to the deeper surrounding tissues by tissue invasion or by circulation route which might lead to incomplete removal of few cell nests during surgery. Besides the lot of stress and immune compromised condition undergone by the animal during the course of four months' time, persistent aetiologies like chronic irritation due to prolonged exposure to sunlight, flies and circumocular a pigmentation also might have acted as predisposing factors for recurrence of ocular tumor.

BCG vaccine stimulates $B$ and $T$ cells and natural killer cells activity. Natural Killer cells stimulates interferons and cytokines. Interferons stimulate antitumor activity of macrophages. Natural killer cell increases histocompatibility antigen resulting in promoting immunity and interrupt the neoplastic process of squamous cell carcinoma in cattle (Radhakrishnan et al., 1999).

The recurrence of the ocular tumor observed in one cow after four months might be due to invasion of the cancerous cell to the deeper surrounding tissues Besides the lot of stress and immune compromised condition undergone by the animal during the course of four months' time, persistent aetiologies like chronic irritation due to prolonged exposure to sunlight, flies and circumocular apigmentation also might have acted as predisposing factors for recurrence of ocular tumor.

In group II, all animals recovered with no recurrence of ocular tumor after observation period of six months (Fig. 4). This finding was in accordance with Prasanna (2020). Rayner and Van (2006) and Malalana et al., (2010) who observed, equine ocular squamous cell carcinoma was successfully treated with Mitomycin eye drops without any recurrence after LASER ablation. Chen et al., (2004), Gupta and Muecke (2010), Walia et al., (2016), Merlak et al., (2017) and Antonietta Blasi et al., (2018) treated ocular surface squamous neoplasia using Mitomycin without any recurrence in humans.

Mitomycin $\mathrm{C}$ belongs to the class of antitumor antibiotics isolated from Streptomyces caespitosus. It is a potent alkylating agent which leads to bifunctional alkylation, in turn cross linking of double helical DNA. Mitomycin is not specific to any stages of cell cycle. It is highly effective in destructing cancer cell (Verweij and Pinedo 1990). 
Fig.1 Well differentiated SQCC

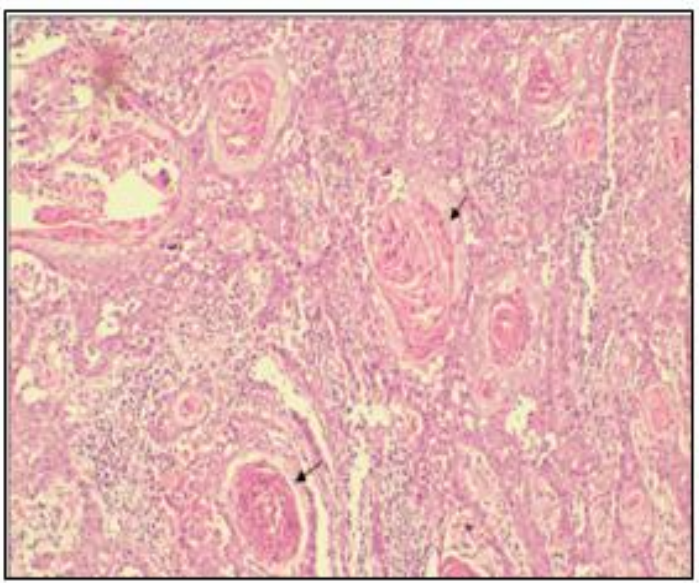

Fig.2 Poorly differentiated

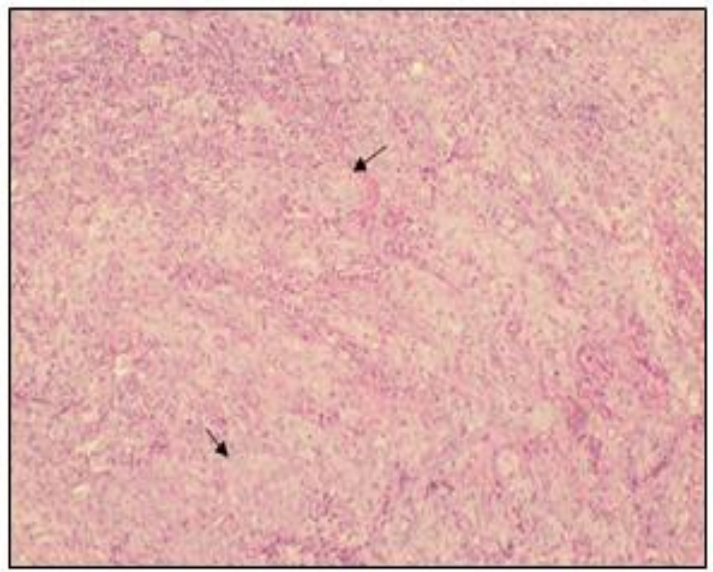

Fig.3 Showing cattle (No.3) in Group A treated with BCG vaccine after surgical excision of third eyelid tumor

Before surgery

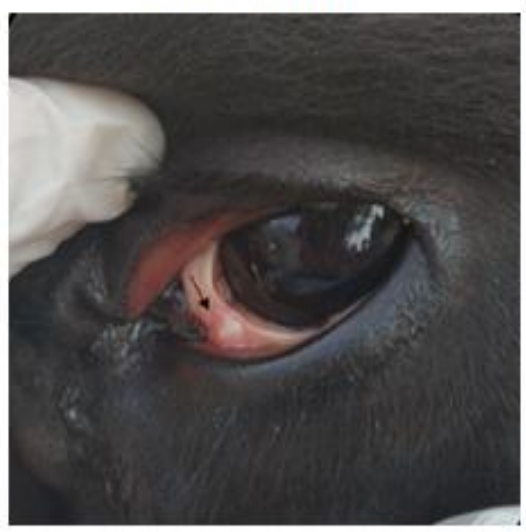

After surgery

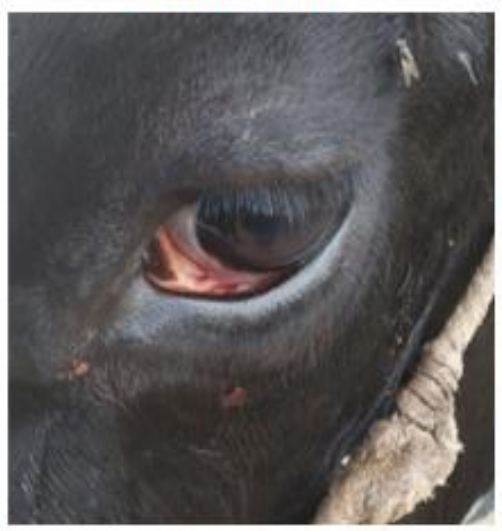

After 6 months

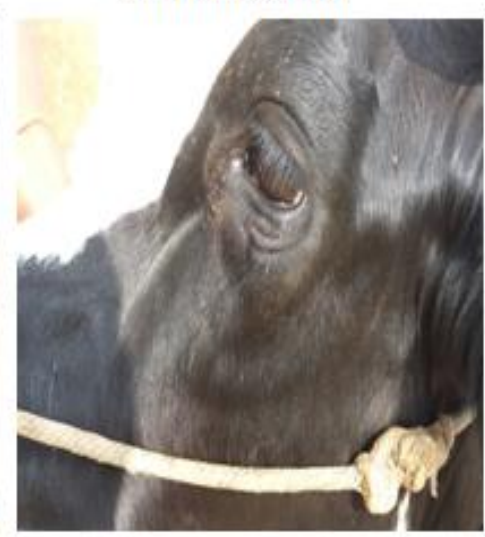

Fig.4 Showing Cattle (No.5) in Group B treated with $0.04 \%$ Mitomycin C eye drops after surgical excision of third eyelid tumor
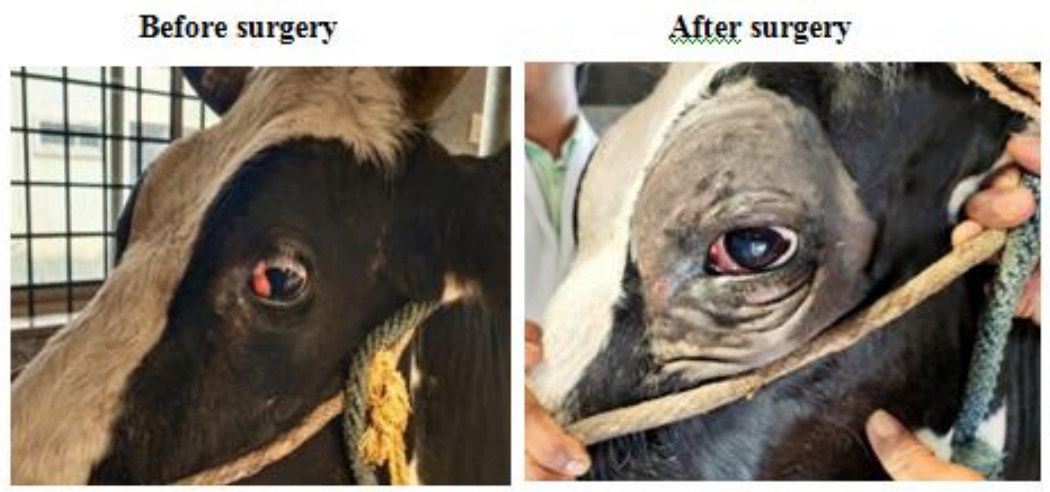

After 6 months

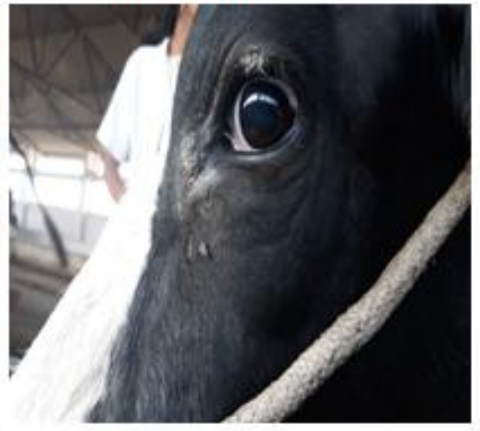

Ocular squamous cell carcinoma is highly is not a complete cure, $40-50 \%$ recurrence invasive malignant tumor. Surgical treatment rates could be expected after surgical 
treatment. Prevention of recurrence is achieved by use of adjunctive therapy. Mitomycin $\mathrm{C}$ is marginally a better adjuvant therapeutic agent compared to $\mathrm{BCG}$ vaccine in terms of recurrence, ease of administration of the drug.

\section{References}

Antonietta Blasi, M., Maceroni, M., Grazia Sammarco, M. and Pagliara, M. M. 2018. Mitomycin C or interferon as adjuvant therapy to surgery for ocular surface squamous neoplasia: comparative study. Eur. J. ophthalmol., 28(2): 204-209.

Chen, C., Louis, D., Dadd, T. and Muecke, J. 2004. Mitomycin c as an adjunct in the treatment of localised ocular surface squamous neoplasia. Br J Ophthalmol., 88: 17-18.

Dilipkumar, D. and Patil, M. 2016. Successful management of eye cancer in deoni cattle: a review of 10 cases. Vet. Pract., 17(2): 213-215.

Gupta, A. and Muecke, J. 2010. Treatment of ocular surface squamous neoplasia with Mitomycin C. Br J Ophthalmol., 94(5): 555-558.

Heeney, J. L. and Valli, V. E. O. 1985. Bovine ocular squamous cell carcinoma: An epidemiological perspective. Can. J. Comp. Med., 49: 21-26.

Malalana, F., Knottenbelt, D. and Mckane, S. 2010. Mitomycin C, with or without surgery, for the treatment of ocular squamous cell carcinoma in horses. Vet. Rec., 167(10): 373-376.

Merlak, M., Babic, M. B. and Dekanic, A.
2017. Treatment of ocular surface squamous neoplasia: case report. Medicina Fluminensis., 53(2): 236240.

Panchbhai, V. S., Kulkarni, P. E. and Deshpande, B. B. 1987. Some observations on ocular growths in cattle. Indian Vet. J., 64: 29-32.

Prasanna, M. L. (2020). Clinical studies on eye cancer in cattle. M.V.Sc. Thesis, Sri Venkateshwara Veterinary University, Tirupati, Andrapradesh.

Radhakrishnan, C., William, B.J., Dharmaceelan, S. and Nagarajan, L.1999. A successful treatment of bovine ocular squamous cell carcinoma by surgery and immunotherapy- a report of two cases. Indian Vet. J., 76: 245- 246.

Schwink, K. 1987. Factors influencing morbidity and outcome of equine ocular squamous cell carcinoma. Equine Vet. J., 19(3): 198-200.

Taylor, S. and Haldorson, G. 2013. A review of equine mucocutaneous squamous cell carcinoma. Equine Vet. Educ., 25(7): 374-378.

Verweij, J. and Pinedo, H. M. 1990. Mitomycin $\mathrm{C}$ : mechanism of action, usefulness and limitations. Anticancer Drugs., 1(1): 5-13.

Walia, S., Srivastava, K. S., Bhaisare, V., Sharma, V., Agarwal, D. and Mandraha, P. 2016. Treatment of ocular surface squamous neoplasia (OSSN) with surgical excision and adjunctive topical mitomycin c therapy. Indian J Med Res., 4(4): 324328.

\section{How to cite this article:}

Priyanka, N., B. N. Nagaraja, N. Nagaraju, D. R. Manjunath and Balapannavar, B. R. 2021. Comparison of Bacillus Calmette Guerin (BCG) Vaccine and Mitomycin $\mathrm{C}$ as an Adjuvant Therapy after the Surgical Excision of Bovine Ocular Squamous Cell Carcinoma. Int.J.Curr.Microbiol.App.Sci. 10(07): 422-426. doi: https://doi.org/10.20546/ijcmas.2021.1007.046 